Vol. 13(18), pp. 1915-1919, 30 April, 2014

DOI: $10.5897 / A J$ B2014.13732

Artic le Number: 6E3744A44439

ISSN 1684-5315

Copyright (c) 2014

African Journal of Biotechnology

Author(s) reta in the copyright of this artic le

http://www.academic joumals.org/A] B

\title{
Investigation of carrier oil stabilized iron oxide nanoparticles and its antibacterial activity
}

\author{
K. L. Palanisamy ${ }^{1 *}$, V. Devabharathi ${ }^{2}$ and N. Meenakshi Sundaram ${ }^{3}$ \\ ${ }^{1}$ Department of Physics, Sengunthar Engineering College, Tiruchengode, India \\ ${ }^{2}$ Department of Physics, KSR Institute of Engineering and Technology, Tiruchengode, India \\ ${ }^{3}$ Department of Biomedical Engineering, PSG College of Technology, Coimbatore, India
}

Received 17 February, 2014; Accepted 29 April, 2014

\begin{abstract}
Iron oxide nanoparticles were synthesized by co-precipitation method. The polyunsaturated carrier oil (flaxseed oil) is used as a stabilizing agent for iron oxide nanoparticles. Kirby Bauer method was used to investigate the antibiotic sensitivity of carrier oil stabilized and uncoated SPIONs at 10 and $20 \mu \mathrm{g} / \mathrm{L}$ on Gram-positive bacterium Bacillus cereus (vegetative cell). The nanoparticles were characterized by X-ray diffraction method (XRD), Fourier transform infrared red (FTIR) analysis, particle size analyzer and Transmission Electron Microscopy. Structure of magnetite nanoparticles was confirmed by XRD analysis and the estimation of nanoparticle size was confirmed with TEM. The attachment of functional groups of oil was predicted using FTIR spectroscopy. This comparison study revealed that carrier oils stabilized iron oxide nanoparticles show more antibacterial activity than the bare iron oxide nanoparticles.
\end{abstract}

Key words: Iron oxide nanoparticles, flaxseed oil, Bacillus cereus

\section{INTRODUCTION}

The Iron oxide nanoparticles can be synthesized by coprecipitation method. The nanoparticles of iron oxide such as $\mathrm{Fe}_{3} \mathrm{O}_{4}$ and $\mathrm{y}-\mathrm{Fe}_{2} \mathrm{O}_{3}$ are very prominent materials in biomedical applications (Sun et al., 2007; Lee et al., 2004; Pan and $\mathrm{Yu}, 2009$ ). The prevention of agglomeration is critical a factor during the synthesis and it can be controlled by appropriate stabilizer, but the stabilizing agent should ensure its function and not to have any effect on the toxicity of the nanoparticles. In this work, flaxseed oil (linseed oil) is used as a stabilizing agent. Flaxseed oil is a colourless to yellowish oil obtained from the dried, ripened seeds of the flax plant (Linum usitatissimum, Linaceae). Flax-based oils are sought after as food because of their high levels of poly unsaturated $\alpha$-linolenic acid (C18:3) (Figure 1), which is a one form of omega-3 fatty acid. The other fatty acids, oleic acid (monosaturated - omega -6 - C18:1), saturated palmitic acid (C16:0) and stearic acid (C18:0) are also constituted (Angerer and von Schacky, 2000; Balk et. al., 2006; Barceló-Coblijn et al., 2008; Barre et al., 2009). Linseed oil is an edible oil marketed as a nutritional supplement (Bassett and Rodriguez-Leyva, 2009). Some

*Corresponding author. E-mail: klpphysics@gmail.com. Tel: +9199651-39339. Fax: 91-4288-255716.

Author(s) agree that this article remain permanently open access under the terms of the Creative Commons Attribution License 4.0 International License 


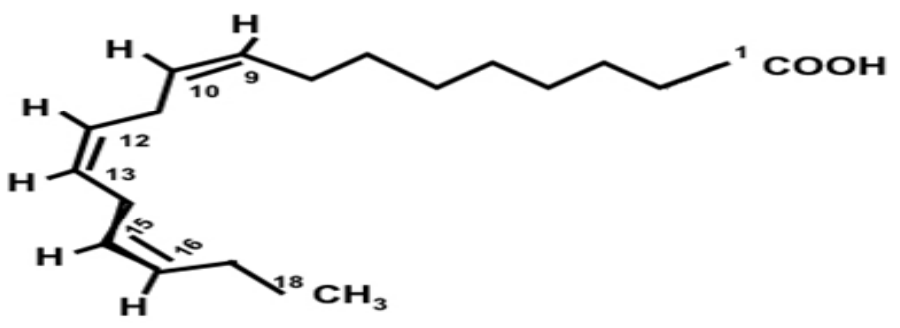

Figure 1. Structure of $\alpha$-linolenic acid.

studies suggest that $\alpha$-linolenic acid (a substance found in flaxseed and flaxseed oil) may benefit people with heart disease (Bays 2007; Hou et al., 2007; Ye et al., 2006).

The antibacterial test on Bacillus cereus (B. cereus) was studied using this flaxseed oil stabilized iron oxide nanoparticles. $B$. cereus is a bacterium that is commonly associated with large outbreaks of food borne illness. $B$. cereus has a wide distribution in nature, frequently isolated from soil and growing plants, but it is also well adapted for growth in the intestinal tract of insects and mammals.

\section{MATERIALS AND METHODS}

All the chemicals were of analytical reagent graded and used without further purification. Ferrous sulphate $\left(\mathrm{FeSO}_{4}, 99 \%\right)$, ferric chloride $\left(\mathrm{FeCl}_{3}, 99 \%\right)$ and Sodium hydroxide $(\mathrm{NaOH})$ were obtained from Merck (India). Flaxseed oil was obtained from Falcon Industries, India. The Gram-positive bacterium B. cereus was purchased from Institute of Microbial Technology (Chandigarh, India), India.

Coprecipitation method was adopted for making the iron oxide nanoparticles. A $100 \mathrm{ml}$ of $0.4 \mathrm{~mol} / \mathrm{L}$ solution $\mathrm{FeCl}_{3}$ and $100 \mathrm{ml}$ of $0.2 \mathrm{~mol} / \mathrm{L} \mathrm{FeSO}_{4}$ were mixed and dissolved in deionized water. Then $2 \mathrm{~mol} / \mathrm{L}$ of sodium hydroxide was added into the above solution and the $\mathrm{pH}$ value between 10 to 11 was maintained with continuous stirring using a magnetic stirrer for $1 \mathrm{~h}$ and a dark precipitation was formed. $5 \mathrm{ml}$ of flaxseed oil was taken and heated to $80^{\circ} \mathrm{C}$ in hot air oven and added in the precipitated solution for stabilization. The precipitated iron oxide particles were washed several times with double distilled water and filtered. Then it was dried at $150^{\circ} \mathrm{C}$ for $2 \mathrm{~h}$ and grinded to fine powder. Then the same procedure was followed for preparing bare iron oxide nanoparticles without adding of flaxseed oil.

$X$-Ray diffraction (XRD) patterns were recorded with a Philips analytical X-ray diffractometer using CuKa radiation $(\lambda=1.5406 \AA)$. FTIR spectra were performed and recorded with a Fourier transform infrared spectrophotometer of type Nicolet 870 . TEM was recorded using Philips CM12 model. Particle size analysis was done by Malvern (U.K.) Make 2000E model.

\section{Determination of antibacterial activity by well-diffusion method}

Antimicrobial assay for the synthesized iron oxide nanoparticles were performed against Gram-positive $B$. cereus by Kirby-Bauer disk diffusion method. The pure cultures of organisms were subcultured in Müller-Hinton broth at $121^{\circ} \mathrm{C}$ at 15 psi for $45 \mathrm{~min}$ in an autoclave. The medium is poured into sterile Petri plate and incibated at $37^{\circ} \mathrm{C}$ for $24 \mathrm{~h}$ to check the plate sterility. The overnight grown $B$. cereus $\left(4 \times 10^{9}\right)$ count was taken and swabbed on three dimensional lawn types on Mueller Hinton agar (MHA) plates. The sterile disc was coated with $10 \mu \mathrm{g} / \mathrm{L}$ of each nanoparticle fix on the top surface of the medium. In another case $20 \mu \mathrm{g} / \mathrm{L}$ of each nanoparticle was coated and fixed on the top surface of the medium. The plates were incubated at $37^{\circ} \mathrm{C}$ for $24 \mathrm{~h}$ and observed for every $4 \mathrm{~h}$. It was observed that the zone of lysis was increasing on prolonged incubation. After $24 \mathrm{~h}$ incubation the plates were examined for the appearance of zone of inhibition. The zone of inhibition was measured in $\mathrm{mm}$ and recorded.

\section{RESULTS AND DISCUSSION}

XRD analyses confirmed that the synthesized nanoparticles were iron oxide nanoparticles as shown in Figure 2 The characteristic peaks were marked by their $2 \theta$ angles and compared with JCPDS data. The planes (2 20$)$, (3 1 1), (4 00 0), (4 $\left.\begin{array}{lll}4 & 2\end{array}\right),\left(\begin{array}{lll}5 & 1 & 1\end{array}\right)$ and (4 $\left.4 \begin{array}{ll}4 & 0\end{array}\right)$ were observed for the corresponding angles of both the samples. The particle sizes were evaluated from the XRD data using the Debye - Scherrer equation and the average particle sizes of the flaxseed oil stabilized iron oxide nanoparticles were 32 and $52 \mathrm{~nm}$ for the uncoated sample.

The surface modification of the iron oxide nanoparticles with their stabilization was confirmed by Fourier transform infrared spectroscopy measurements (FTIR) (Figure 3). The presence of absorption peaks in the region of wave numbers 550 to $630 \mathrm{~cm}^{-1}$ corresponding to the $\mathrm{Fe}-\mathrm{O}$ vibration. The peaks at $3434 \mathrm{~cm}^{-1}$ in Figure 2a and 3442 $\mathrm{cm}^{-1}$ in Figure $2 \mathrm{~b}$ were related to the vibrations of ${ }^{-} \mathrm{OH}$ and the peaks at $1707,1629,1706$ and $1631 \mathrm{~cm}^{-1}$ were due to the overlapping of the absorption bands of the carboxyl groups and double bond of oleic acid and alinolenic acid, respectively (Lu et al., 2012). The other peaks observed in the region of 882 to $1366 \mathrm{~cm}^{-1}$ in sample (b) were due to the additional compounds (polyphenols, peroxides and polycyclic aromatic hydrocarbons (PAHs), vitamin $\mathrm{K}$ and $\mathrm{E}$ ) present in the oil.

The particle size and the morphology of iron oxide nanoparticles were observed by transmission electron microscopy (TEM). Figure 4 shows TEM micrographs of samples of uncoated and flaxseed oil stabilized iron oxide nanoparticles and these images indicate that the particles are not aggregated and the mean physical sizes were obtained by Debye-Scherer formula. The antibacterial activity of iron oxide nanoparticles of uncoated (a) and flaxseed oil mediated samples were performed against Gram- positive bacterium B. cereus (vegetative cell) at 10 $\mu \mathrm{g} / \mathrm{L}$ and $10 \mu \mathrm{g} / \mathrm{L}$ concentrations using agar well diffusion method. The values of zone of inhibition $(\mathrm{mm})$ of these nanoparticles were presented in the Table 1.

Figures 5 and 6 show the zone of inhibition of bacterial growth on agar plates with two different concentrations of flaxseed oil stabilized and bare iron oxide nanoparticles. It was observed from the images and pie chart that the growth of bacteria was inhibited gradually with increase in 

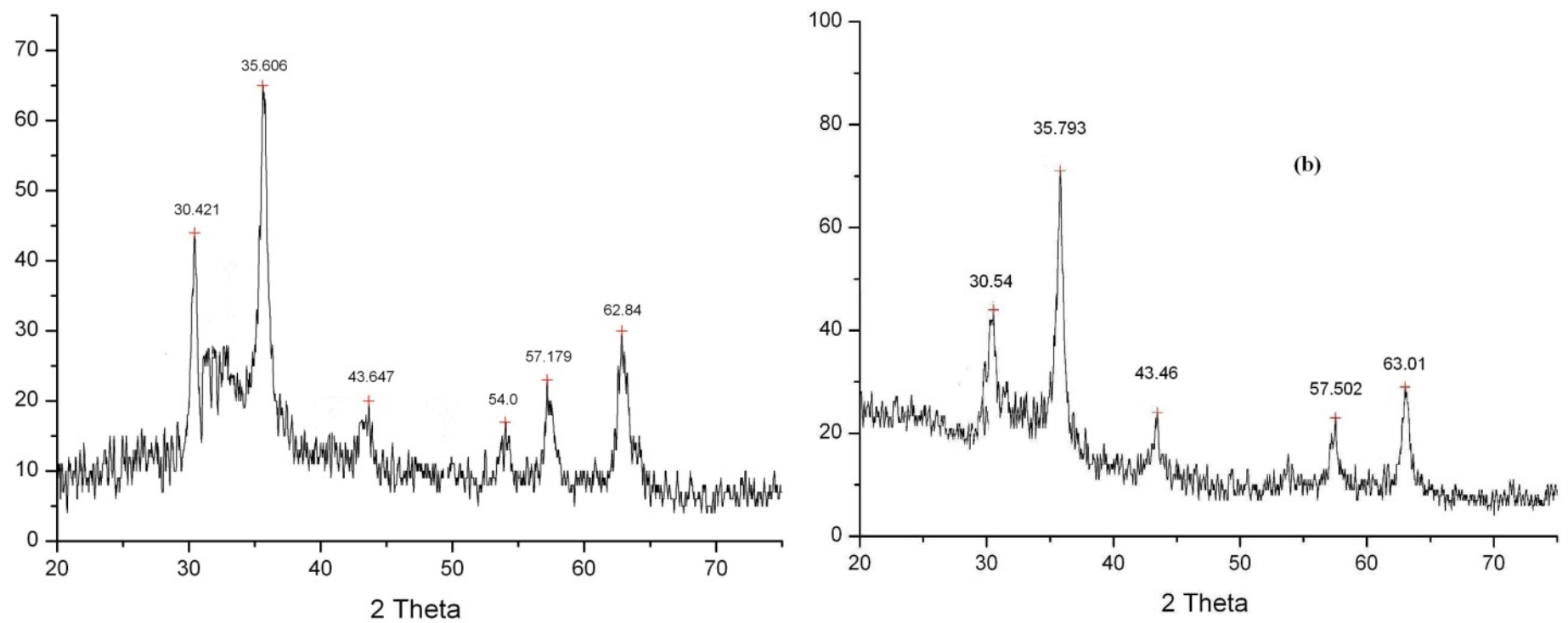

Figure 2. XRD patterns of uncoated (a) and flaxseed (b) iron oxide nanparticles.
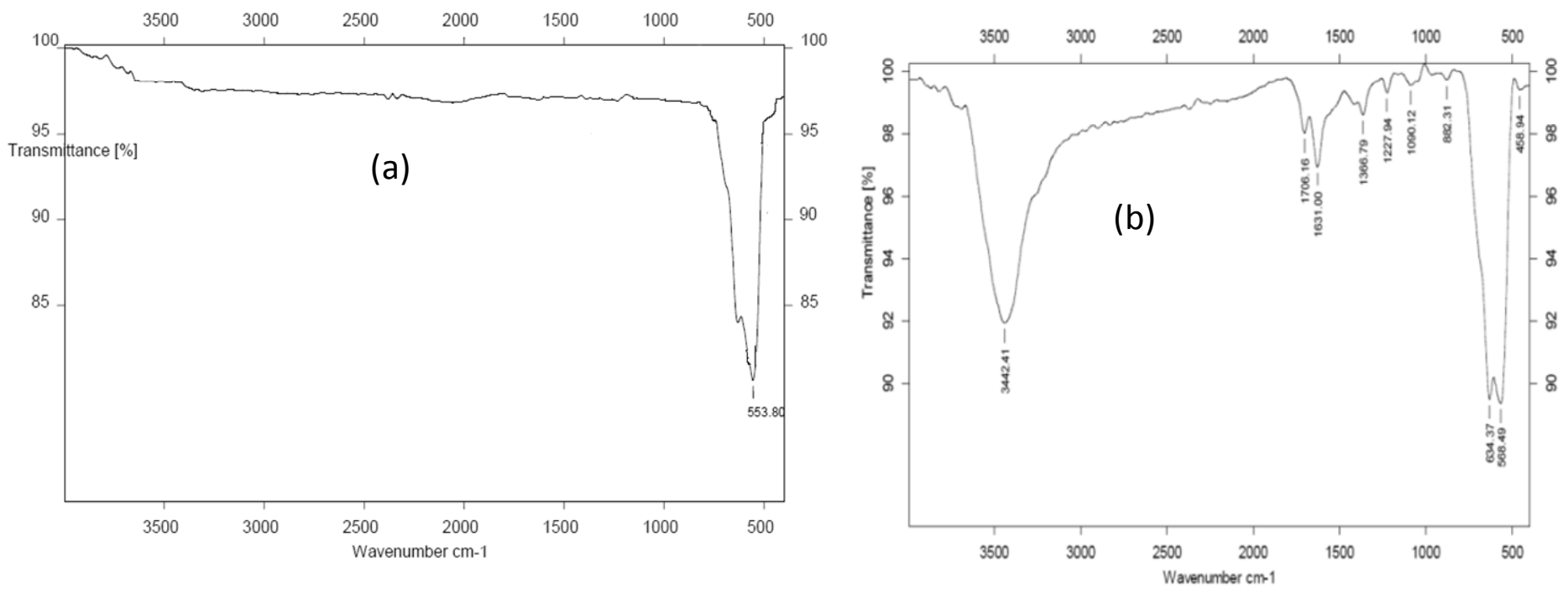

Figure 3. FTIR analysis of uncoated (a) and flaxseed (b) iron oxide nanoparticles.

concentration of iron oxide nanoparticles. Further the results clearly demonstrate that Flaxseed oil mediated iron oxide nanoparticles could promise a better antimicrobial agent than the bare iron oxide nanoparticles.

\section{Conclusion}

In the field of nanotechnology, the development of reliable and eco-friendly processes for synthesizing of metal oxide nanoparticles is very essential. Here, we have reported a simple, eco-friendly and low-cost approach for preparation of magnetite nanoparticles by reduction of ferric chloride solution with a green method using flaxseed oil as the stabilizing agent and compared with the uncoated iron oxide nanoparticles. The characteristics of the obtained iron oxide nanoparticles were studied using FTIR, XRD and TEM techniques. The antibacterial effects of flaxseed oil stabilized iron oxide nanoparticles and bare iron oxide nanoparticles against gram- positive bacterium bacillus cereus (vegetative cell) were investigated.

The results exhibit that the flaxseed oil stabilized iron oxide nanoparticles were less in size, more antibacterial activity than the bare iron oxide nanoparticles. 

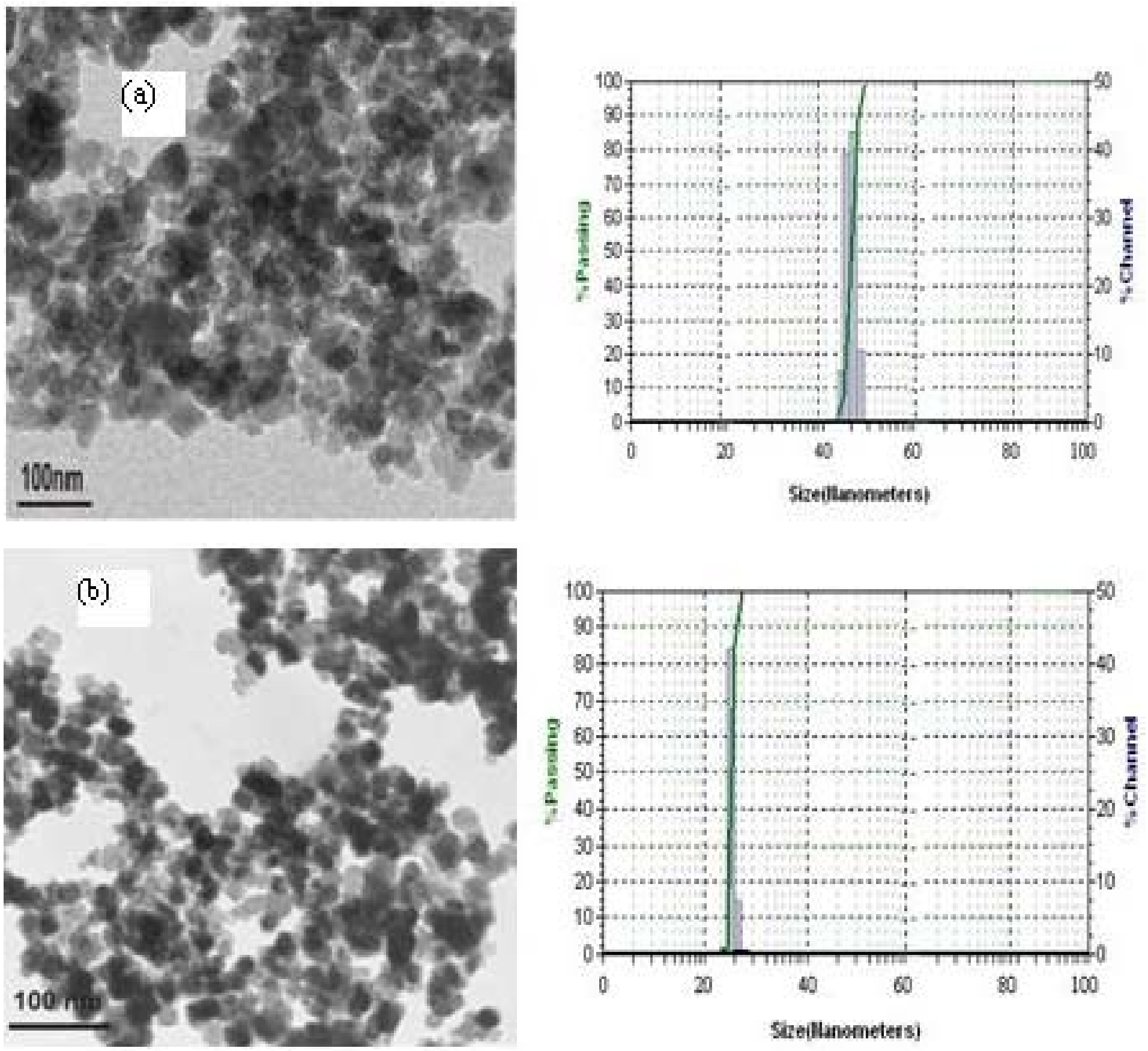

Figure 4. TEM photographs of uncoated (a) and flaxseed (b) SPIONs.

Table 1. Zone of inhibition ( $\mathrm{mm}$ ) for various concentrations of ncoated (a) and flaxseed (b) SPIONs.

\begin{tabular}{clcclc}
\hline & \multicolumn{2}{c}{$\mathbf{1 0} \boldsymbol{\mu g} / \mathrm{L}$ of nanoparticle coated } & \multicolumn{2}{c}{$\mathbf{2 0} \boldsymbol{\mu g} / \mathrm{L}$ of nanoparticle coated } \\
\hline S/N & Nanoparticle & Zone of & S/N & Nanoparticle & $\begin{array}{c}\text { Zone of inhibition } \\
(\mathbf{m m})\end{array}$ \\
\hline 1 & Flaxseed oil stabilized & 3.75 & 1 & $\begin{array}{l}\text { Flaxseed oil stabilized } \\
\text { SPIONs }\end{array}$ & 8.5 \\
2 & SPIONs & 1.5 & 2 & Uncoated SPIONs & 3.5 \\
\hline
\end{tabular}




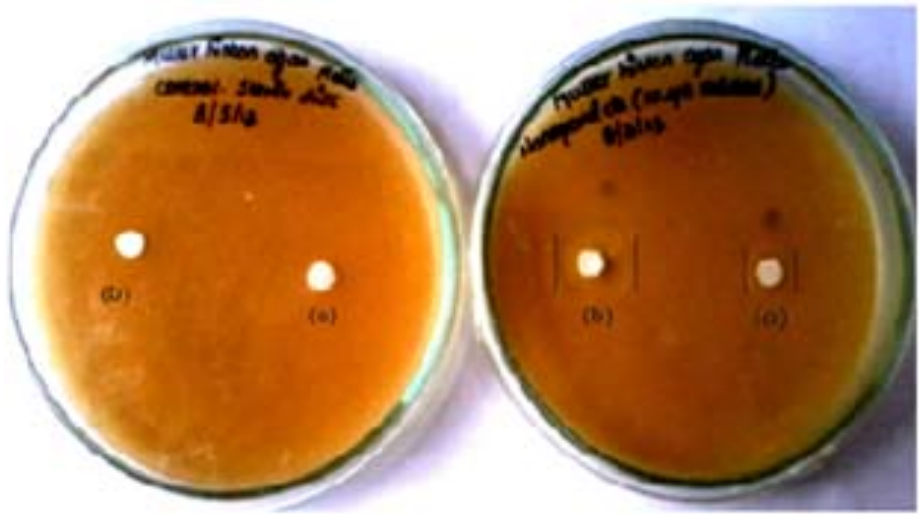

$10 \mu \mathrm{g} / \mathrm{L}$ concentration

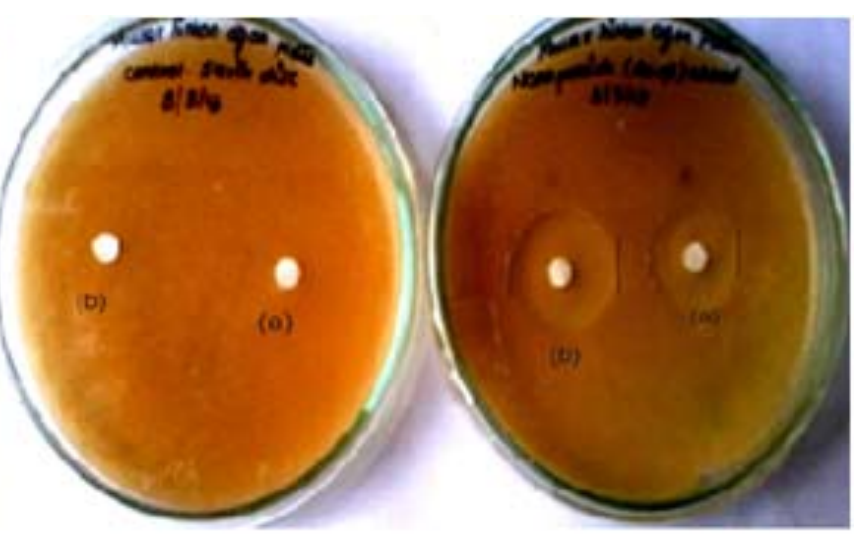

$20 \mu \mathrm{g} / \mathrm{L}$ concentration

Figure 5. Zone of inhibition ( $\mathrm{mm}$ ) of uncoated (a) and flaxseed (b) iron oxide nanoparticles

\section{$10 \mu \mathrm{g} / \mathrm{L}$ of nanoparticle coated}

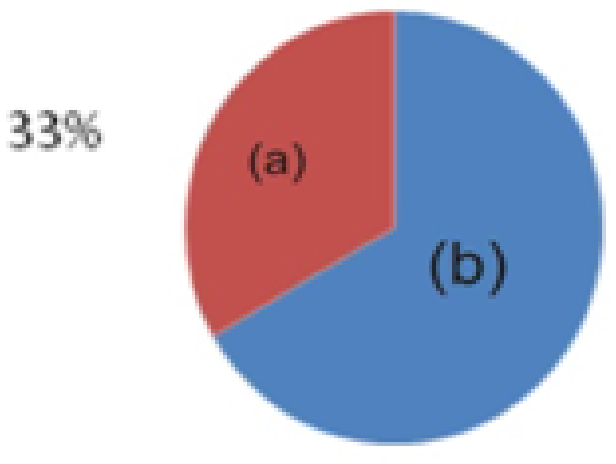

\section{$20 \mu \mathrm{g} / \mathrm{L}$ of nanoparticle coated}

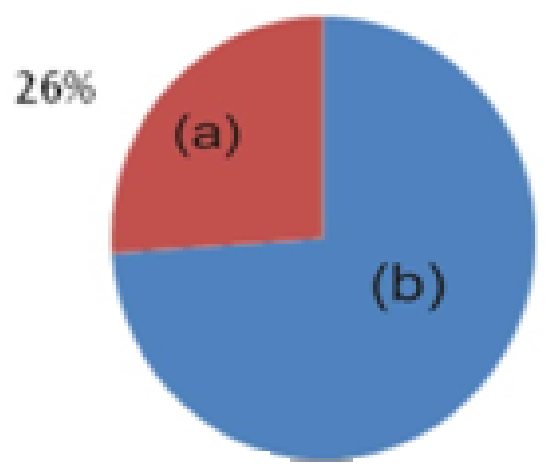

Figure 6. Pie chart zone of inhibition ( $\mathrm{mm}$ ) of uncoated (a) and flaxseed (b) iron oxide nanoparticles.

\section{REFERENCES}

Sun J, Zhou S, Hou P, Yang Y, Weng J, Li X, Li M (2007). Synthesis and Characterization of biocompatible $\mathrm{Fe}_{3} \mathrm{O}_{4}$ Nanoparticles, Wiley periodicals, Inc. J. Biomed. Mater. Res. 333-341.

Lee S, Jeong J, Shin SC, Kim JC, Kim JD (2004). Synthesis and characterization of superparamagnetic maghemite nanoparticles prepared by co-precipitation technique, J, Magnetism and Magnetic Mat. 282:147- 150.

Pan A, Yu D (2009). Demark-Wahnefried W.Meta analysis of the effects of Flaxseed interventions on blood lipids, Am. J. Clin. Nutr. 90(2):288-297.

Angerer $P$, von Schacky $C(2000)$. polyunsaturated fatty acids and the cardiovascular system. Curr. Opin. Lipidol. 11(1):57-63.

Balk EM, Lichtenstein AH, Chung M (2006). Effects of omega-3 fatty acids on serum markers of cardiovascular disease risk: A systematic review. Atherosclerosis. 189(1):19-30.

Barceló-Coblijn G, Murphy EJ, Othman R, Moghadasian MH, Kashour T, Friel JK (2008). Flaxseed oil and fish-oil capsule consumption alters human red blood cell $\mathrm{n}-3$ fatty acid composition: a multipledosing trial comparing 2 sources of $\mathrm{n}-3$ fatty acid. Am J Clin Nutr. 88(3):801-809.
Barre DE, Mizier-Barre KA, Griscti O, Hafez K (2009). Flaxseed oil supplementation increases plasma F1-phytoprostanes in healthy men. J. Nutr. 139(10):1890-1895.

Bassett CM, Rodriguez-Leyva D, Pierce GN (2009). Experimental and clinical research findings on the cardiovascular benefits of consuming flaxseed. Appl Physiol Nutr Metab. 34(5):965-974.

Bays HE (2007). Safety considerations with omega-3 Fatty Acid therapy. Am. J. Cardiol. 99(6A):S35-43.

Hou Y, Xu Z, Sun S (2007). Controlled Synthesis and chemical Conversions of FeO Nanoparticles, Angew. Chem. Int. Ed. 46:6329 6332X.

Ye R, Daraio C, Wang C, Talbot JB, Jin S (2006). Room temperature solvent-Free Synthesis of Monodisperse Magnetite Nanocrystals, J. Nanoscience Nanotechnol. 6:852-856.

Lu C, Bhatt LR, Jun HY, Park SH, Chai KY (2012). Carboxyl-polyethylene glycol-phosphoric acid: a ligand for highly stabilized iron oxide nanoparticles, J. Mater. Chem., 22:19806-19811. 